\title{
6
}

\section{Respiratory technologies and the co-production of breathing in the twentieth century*}

\section{Coreen McGuire, Jaipreet Virdi and Jenny Hutton}

In 1933, Nobel prize-winning physicist William H. Bragg (1862-1942) was worried about his neighbour, Capt. Samuel Crosby Halahan (1869-1939), who lived in West Sussex and suffered from what Bragg described as a 'terrible wasting of the muscles'. ${ }^{1}$ Not much is known about Halahan's life other than his military service and that his friendship with Bragg resulted in the design of a new homemade 'breathing machine'. In 1926, Halahan began gradually to lose weight as well as all 'power of moving his limbs' until he was unable to drive a car or write. Halahan also lost the ability to breathe unaided, therefore eventually requiring the care of two nurses:

For a long time two nurses were employed giving artificial respiration continually: the wife felt very much the disability of being unable to speak to him except in the presence of a nurse because her strength had considerably diminished due to the strain of her husband's illness, and she was unable therefore to give artificial respiration herself. ${ }^{2}$

It is unclear what kind of artificial respiration Halahan was given, though the nurses probably employed a manual lung-inflation device such as the McKesson resuscitator, rather than attempting to maintain purely manual inflation. Halahan needed such continuous artificial respiration from the onset of paralysis in 1931 until his death in 1936 at the age of sixty-six. ${ }^{3}$ His respiratory paralysis was diagnosed as resulting from progressive muscular atrophy.

Given the strain that continuous artificial respiration placed on Halahan's relationship with his wife, Bragg 'had the idea that [he] 
could ease matters by a simple system of india [sic] rubber bladders, football bladders in fact' to substitute the human effort. To devise this automated system, he bandaged one of the bladders under a binder on Halahan's chest and the other to a pair of hinged boards on the ground, then connected the two with a long tube. This bellows device applied rhythmic pressure directly to the chest, forcing the diaphragm to contract and air to enter and leave the lungs. Rather than continuously pressuring the chest with her hands, a nurse or Halahan's wife, Maud (1872-1967), could apply pressure, by simply pressing down on the hand lever that connected to the pulsating rubber bellows. ${ }^{4}$ Bragg's invention used positive pressure which meant that it enforced expiration of air by forcing the ribs in, much like the manual ventilation methods more commonly associated with drowning. The device's mechanism, however, only lasted three days before the rubber burst, eventually being replaced by a hot water bottle used as an airbag. Again, the materials proved to be insufficient. The revised design lasted just another three weeks after being replaced and patched. Then the hinges attached to the original boards became loose. ${ }^{5}$ A substitute was created by a 'firm of organ builders', but this proved too hard for the nurse to manoeuvre, especially since no means of electric supply was available.

Despite the mechanical improvement, the labour remained arduous for the nurses and Maud, so Bragg commissioned instrument maker Robert W. Paul (1869-1943) to construct a small hydraulic machine that relied on the main water supply. ${ }^{6}$ This new design worked effectively - except on occasions when the water pipes froze or the water supply was shut off for repairs without notice - and was estimated to have caused 15 million involuntary respirations in Halahan's lifetime. ${ }^{7}$ It was discreet, as the hollow bandage that replaced the football bladder could be hidden by the bedcovers so 'that there was no evidence of anything unusual except the quiet click-clack of the pulsator in another part of the room' ${ }^{8}$ Furthermore, it made Halahan's relationships easier, as Maud could 'give artificial respiration while she sits and reads to her husband' and only one nurse was required to assist. ${ }^{9} \mathrm{He}$ wore the device up to seventeen hours each day, as he could not 'bear the constriction of the bandage' all day; the remaining hours were filled with manual respiration. ${ }^{10}$ Bragg's portable system offered Halahan more mobility and privacy. It also gave him more control over his breathing. The system was 
adjusted to fit to Halahan's body, leaving him 'free to do as much as he could have done if it had not been applied'. ${ }^{11}$ It was even allegedly modified so that it could be used while driving. ${ }^{12}$

As Coreen McGuire and Havi Carel have elucidated, the elements of co-production in its origins of design involved engagement with the patient's needs beyond the strictly medical. ${ }^{13}$ The story of Bragg and Halahan's friendship and collaboration encapsulates many of the themes we explore in this chapter, in which we analyse how bodily knowledge and insight influenced the design of technological support for respiratory disability. Our chapter is primarily focused on twentieth-century developments to respiratory technologies in Britain and will analyse the extent to which consideration of users and user involvement featured in technologies designed to facilitate breathing. We use this user-focused framework to examine respirators like Bragg and Paul's device, which became commercialised as the 'Pulsator' during the interwar period, as well as oxygen-based therapy used in the hospital and the home. ${ }^{14}$ With the exception of Halahan's story, recovering these machine users' voices is challenging as they are often filtered in the historical record through the voices of designers, physicians and family members. We refer to patients in this chapter primarily as users for manifold reasons, applying a 'social construction of technology' approach to highlight the contributions of patients to design. In this way, our examination of breathing and assistive technologies links directly to the new ways of locating patient voices outlined in this collection. Following historically appropriate terminology outlined by the Medical Research Council (MRC), we refer to 'breathing machines' for apparatuses used to stimulate breathing artificially over prolonged periods of time. The term 'respirator', however, is also commonly applied to machines that supply oxygen (or oxygen and carbon dioxide). ${ }^{15}$ The terminological conflation of the two is rooted in the longer history of artificial respiration. Respirators originally referred to mask type coverings that were popularised in the Victorian era as a health tool used to warm the air prior 'to its entering the mouth, or nose, in respiration' especially in cold weather and for users 'in delicate health'. ${ }^{16}$ Rudimentary homemade respirators were also used (to little effect) by firefighters and coalminers attempting to keep their lungs free from dust and debris. However, by the 1930s, the term respirator was more commonly used in relation to the 'mechanical respirators' that 
were used to stimulate artificial breathing in patients with respiratory paralysis, which generally occurred as a result of polio. These 'breathing machines' are like modern-day ventilators in the sense that they 'breathe' for those who cannot; but differ in that ventilators of today use masks or (more often) breathing tubes inserted into the windpipe or through a tracheostomy. We also discuss the ambulatory oxygen devices which provide supplemental oxygen to people with low oxygen levels.

All such devices are characterised by an intimate proximity to their users' bodies and both mediate the reception of oxygen into the body and thus have a symbolic relationship to our understandings of breath as associated with voice, life and death. ${ }^{17}$ These technologies followed disparate pathways of development: while mechanical respirator designs were characterised by user involvement, ambulatory oxygen was initially designed within emergency medicine for use on patients as passive recipients in a hospital setting. This approach can lead to lack of consideration of the lived experience of patients using such devices.

For instance, in the early stages of the COVID-19 pandemic there were worldwide shortages of the ventilators necessary to treat patients suffering from the worst effects of the virus, and British government officials were criticised for commissioning non-specialist engineering firms without consulting medical experts. ${ }^{18}$ Reliance on a hastily assembled industry consortium means that the resulting basic design does not include key features, most notably those intended to ensure the comfort of patients such as 'spontaneous breathing modes' which allow the patient to breathe in synchronicity with the device, making it easier for them to be weaned off the machine. ${ }^{19}$ Prioritising cost efficiency over patient need is especially dangerous because breathing, while universal, is characterised by extreme subjectivity and variability. One size will never fit all when it comes to breath prosthetics. We can see this by reviewing the discussions of ambulatory oxygen for home use after its introduction in 1968, through which we can assess the extent to which concerns about costs and the possible dangers of oxygen toxicity outweighed consideration of patient's non-medical needs. Consideration of the weight of the object, its portability, appearance and noise level, was secondary to its cost efficiency. As disability scholars have demonstrated, the frequent disjunct between the medical design of prosthesis and the needs of 
intended users has often stemmed from the medical model of disability. ${ }^{20}$ The medical model paradigm defines disability as a loss of function or impairment, which medical intervention ideally would be able to cure. This is in opposition to the social model of disability, which attributes the discrimination and problems faced by disabled people as wholly resulting from the society in which they live. Prosthetic technologies have thus been criticised as being a 'technological fix' for problems which are in fact more social than medical. ${ }^{21}$

Not all prosthetic designs fit easily within the medical/social model binary. Hearing assistive devices, for instance, rely on the embodied knowledge of the user and have often been designed in co-production with people with hearing loss. ${ }^{22}$ The process of co-production then, may be particularly important in devices used in conditions like breathlessness, which is usually personal, invisible and intimate. However, the crucial role of the patient/user is frequently devalued within the medical model paradigm.

In what follows, we start our chapter by outlining the twentiethcentury developments to mechanical respirators which set up use of the Bragg-Paul Pulsator in opposition to iron lung style devices. The dichotomy presented between these two machines reflected the tension between the heterogeneity of individual breathing and the need for a standardised breathing machine. This need for technological consistency was especially important to the MRC. Indeed, their interwar report on 'breathing machines' reveals that their drive for standardisation worked in opposition to patients' diverse experiences of these machines. As well, there are many parallels between the current ventilator procurement programme and the interwar debate over respiratory technologies. Who ought to be responsible for providing and perfecting such technologies? Should respiratory technologies be designed by engineers or by medical men? Or by those using the technologies themselves? How were users' voices heard in the context of this debate? These questions crystallised around the MRC's crucial interwar debate about which breathing machines were best: those using negative pressure or those using positive pressure. In this chapter we analyse the extent to which users were involved in this debate. We also explore how the eventual emergence of the iron lung as the standard 'breathing machine' shaped patients' experiences in hospitals in the post-war period. And, finally, we reflect on how diverse patient needs were incorporated 
into the administration of portable oxygen concentrators in the context of the National Health Service (NHS).

\section{Mechanical respirators, 1930-39}

In the 1930s, the application of respiratory technologies increasingly focused on respiratory paralysis caused by the polio epidemics that seasonally ravaged Britain. The MRC estimated in 1939 there were at least 600 cases of respiratory paralysis a year that required technological intervention to assist in breathing. ${ }^{23}$ The term 'iron lung' respirator - a negative pressure ventilator to assist in breathing when muscle control is lost or limited - was often used in general terms as an eponym in the interwar period for any kind of respirator, but the machine was actually one of many technologies adapted at the time to enable artificial breathing. The first 'iron lungs' were designed in the United States at Harvard University by Philip Drinker (1894-1972) and Louis Agassiz Shaw Jr. (1886-1940). These machines used negative pressure to create a vacuum and force a patient's diaphragm to expand and contract to exert alternating pressure through a push-pull motion. ${ }^{24}$ By regulating the rate and depth of respiration, the device allowed for prolonged artificial respiration, either until the patient recovered muscle strength or until an alternative method of treatment became available.

The Drinker respirator, as it became known, was first used in Britain in 1930. ${ }^{25}$ However, it was expensive: costs ranged from $£ 200$ to $£ 2,000$ depending on export fees. Bulky and heavy, it was difficult to transport. Moreover, some hospitals lacked the necessary funds and space for obtaining the machine. Indeed, even though Drinker and Edgar L. Roy offered instructions for building an emergency makeshift respirator with common hardware materials, the apparatus was not as widely used in Britain as in the United States. ${ }^{26}$ It was eventually superseded by Australian inventor Edward T. Both's (1908-87) plywood-based iron lung, which was presented as a more affordable alternative. ${ }^{27}$ Like the Drinker respirator, the Both iron lung required the patient to be entirely encased in a cabinet with only their head protruding out with only the capacity to eat, drink and sleep. ${ }^{28}$ The depth and rate of breathing was controlled by an attendant, not by the patient. ${ }^{29}$ One user described the challenge 
of moderating eating and breathing patterns to the machine by explaining that:

You can eat in the iron lung because your head is outside but the rest of your body is inside, although since you are flat on your back you really need to be careful when you swallow; you have to swallow in rhythm with the machine because it's pulling your diaphragm in and then pushing it out again. You just wait until it's breathing out and then you swallow. Coughing was a bit more difficult because you don't cough in rhythm with the iron lung. It was something you had to work around. ${ }^{30}$

By comparison, through using positive pressure to force expiration of air, the Bragg-Paul Pulsator represented a cheap and portable alternative to the iron lung respirators, designed so that it could be carried by a single porter for use in a private home or ward. ${ }^{31}$ Bragg's initial iteration worked through manual rhythmical manipulation of the pump, with Paul ensuring that the bellows could also be actuated by hand if needed. Yet, even though their design provided greater agency to the patient by freeing them from completely mechanised enclosure, the breathing was still controlled by an attendant. This reliance and the need to protect the Pulsator against any unforeseen complications (e.g. electrical or water failures) meant that Halahan was never left alone. He was also to use his tongue and teeth without breath to sound an alarm 'resembling that of a bird' to alert the attendant. ${ }^{32}$ This technique holds parallels with the 'frog breathing' described by Daniel Wilson, which involved patients with paralysed chests utilising the muscles of the neck instead to breathe in a gulping fashion 'like a frog'. ${ }^{33}$

The benefits of a portable, semi-mechanical respirator being widely available were not lost on Bragg and Paul. Indeed, as early as 1933, Bragg contacted several hospitals to inquire as to whether there was any medical interest in the Pulsator. One reply, from K.N. Knapp of Swindon and North Wilts Victoria Hospital, agreed that it would be beneficial to have the device in the hospital and that such 'a semi-mechanical respirator would often be most useful, and would save labour and Staff'. ${ }^{34}$ Knapp also advised Bragg to contact physiologists to improve the mechanisation of the device. In January 1934, Bragg invited physiologist A.V. Hill (1886-1977) to inspect the machine and asked whether he had any suggestions for its 
improvement. ${ }^{35}$ Hill suggested Paul contact Dr Edward Poulton at the London School of Hygiene and Tropical Medicine, to help work out how to standardise the measurements of ventilation efficiency needed for different patients. ${ }^{36}$ This was a necessary step for allowing large-scale usage of the respirator and for its incorporation into a hospital setting.

Intrigued by the device, Poulton agreed that the Pulsator should be widely distributed to hospitals, but before this could be done, the device needed to be put through a series of rigorous physiological tests to determine its efficacy and safety. Subsequently, Poulton hoped to make clinical tests with the device at Guy's Hospital, perceiving its potential value for treating asphyxia in newborns. ${ }^{37}$ To this end, Poulton recommended that Paul should consult physiologist Dr Phyllis Kerridge (1901-40), who would play a pivotal role in making the respirator viable for widespread hospital use and adaptable to different bodies.

After testing the physiological parameters of the device, Kerridge suggested simplifying the 'waistcoat' by adding an airbag lined with canvas and vulcanised together, thereby allowing the lining to circumvent the awkward bellying of the bag. ${ }^{38}$ She suggested this form and mode of application as well as working out the best position of the airbags and the measurements of ventilation efficiency needed to introduce it to the medical profession. ${ }^{39}$ The pressure of the belt could be adjusted, with several sizes available to suit different patients, including infants; the belt was to be worn over an undergarment which would not crease and cause discomfort to the patient's skin. ${ }^{40}$ It also allowed for adjustment to suit individual respiratory rate. ${ }^{41}$

To ensure the Pulsator was available to hospitals, and to popularise it as an alternative to iron lungs, Paul assumed the financial responsibility to order six devices for hospitals using his personal limited funds. Both Bragg and Paul explained that they were not 'financially interested' in their machine and thus chose not to patent it or request royalties. ${ }^{42}$ The machine was then manufactured by the firm Siebe Gorman and Co. (who had made the Haldane gas masks) and they proposed a cost of $£ 30$ which would be worth approximately $£ 1,500$ today. ${ }^{43}$ They also substituted steel for brass in certain parts to 'strengthen the design of the apparatus'. ${ }^{44}$ By this stage the Pulsator was electrically driven and Bragg emphasised that this meant it was 'practically noiseless' - an attractive improvement over the Drinker 
respirator, which was notoriously loud. ${ }^{45}$ Its externally audible noisiness was amplified further for users, who could also feel the pump vibrations. Thirteen Pulsators were installed in British hospitals by 1937 (a further six were sent overseas) and another sixteen were on order. ${ }^{46}$ Even more were placed on backorder, perhaps because in 1938 there were several polio outbreaks and an increased number of diphtheria cases requiring ventilators. ${ }^{47}$

The Pulsator's highest profile promotion was given by the BBC on a Friday night on 8 July 1938. The BBC sent out an emergency SOS for a Bragg-Paul Pulsator needed at an Ipswich Hospital to save the life of a child. ${ }^{48}$ One was immediately sent by car from a London Hospital, but the patient died while it was in transit. ${ }^{49} \mathrm{On}$ 14 July 1938, this case was discussed in the House of Commons and the Minister of Health was asked whether he could provide more Pulsators to hospitals throughout Britain to extend coverage from the eighteen already in use. ${ }^{50}$ Similarly, on 24 July 1938, a fifty-eight-year-old man died in the Royal Infirmary in Liverpool after a plane was sent to rush a Bragg-Paul respirator from Ipswich to Liverpool. ${ }^{51}$ Presumably, the respirator had been in Ipswich since it was sent from London previously, and it was immediately sent back by train for another patient. Such well-publicised crises generated a media furore but there was some initial confusion in the press between the Drinker respirator and the Pulsator. Paul hastened to write to Dr Sommerville Hastings following the broadcast to explain the advantages of the Pulsator: 'I, personally, find it hard to imagine the continuous use of the other type for three years on a patient'. ${ }^{52}$ However, Hasting replied that the Drinker respirator was thought by physiologists to be better because it used negative pressure (creating a vacuum) which more closely imitated natural breathing. ${ }^{53}$

\section{Patient experiences in the machine}

The debate over positive versus negative pressure led to the MRC appointing a committee to investigate the best mechanical apparatus for 'preventing asphyxia due to respiratory paralysis'. ${ }^{54}$ This subject demanded immediate attention, as a serious polio epidemic had hit England and Wales in $1938 .^{55}$ Kerridge initially suggested to the Ministry of Health that there should be a large-scale survey on 
infantile paralysis and the potential of artificial respiration. ${ }^{56}$ The Ministry, however, rejected the survey but inquired on the position of the Pulsator in comparison to other artificial respirators, thus forming a 'Respirators (Poliomyelitis) Committee' comprised of eight medical professionals, including Kerridge, and a secretary. ${ }^{57}$ Patients and users were not considered as possible members of this committee, which was convened to 'examine the various forms of machine available and to consider the problem from the physiological point of view' ${ }^{58}$ The study aimed to analyse and compare the relative merits of all available mechanical apparatus for preventing asphyxia following the request from the Ministry of Health. Initially, the committee aimed to evaluate which pressure was best for artificial respiration and thereby conclude whether the Bragg-Paul Pulsator or the iron lung device should be recommended as standard. However, the variability of respiratory conditions under consideration and the complexities of individual cases meant that the report expanded to consider a wide variety of 'breathing machines'.

The committee divided power-driven machines into three categories: first, machines that enclosed the full body of the patient; second, machines that enclosed the body and head; and finally, machines that did not involve total enclosure of the body. These categories suggest how bodily autonomy and movement of the patient were factored into the usefulness and effectiveness of the machines. The Barospirator was invented in 1906 and was the only device that enclosed both the body and the head. It worked like the earlier oxygen rooms, through strict atmospheric controls applied to a large chamber which the patient and up to two others could remain in. The control of carbon dioxide that this necessitated was considered by the committee to be too onerous and so this invention was not given detailed consideration.

Thus, the main debate was between full-body enclosure or not. Full-body enclosure devices included the Drinker respirator, the Drinker-Collins respirator, the Emerson respirator, the Henderson respirator, the Siebe-Gorman 'drinker' respirator and the Both respirator. Devices that worked without full-body enclosure included the Biomotor of Dr Eisenmenger, the Bragg-Paul Pulsator, the Burstall Jacket respirator, the London County Council Cuirass respirator, the Turner Jacket respirator, the Laffer Lewis Apparatus and Eve's Motor Rocking Bed. The latter device worked on a different principle 
from the others: rather than using negative or positive pressure, it used gravity and the weight of the patient to force the diaphragm to move in and out. Such rocking beds were used regularly in the United States on partially paralysed polio patients but this one was presumably included under power driven machines because it used an electronic motor to rock the bed. ${ }^{59}$

In the section of the MRC report on 'preparing the patient for the machine' we find details about what kind of clothes the patient should wear in a box style device. Only pyjama trousers and an undervest were allowed until the patient was secured inside the machine and then the pyjama jacket was put on back to front to avoid skin irritation due to the neck rubbing against the rubber neck-hole. ${ }^{60} \mathrm{~A}$ thin layer of cotton wool was also applied (and held in place with a bandage) to avoid such skin irritation. It was crucial that 'bedsocks' were then worn to avoid chilled feet from the air that rushed in from the suction hole at the end of the machine and blankets were strategically placed to prevent patient complaints of 'cold spots' and to avoid bed sores. Careful consideration of clothing and handling of the patient was important because of patient complaints of extreme tenderness and 'hyperaesthesia' (excessive skin sensitivity) which could make any handling very painful and distressing. ${ }^{61}$ Adjusting the temperature of the patient within the machine was clearly an issue of some concern, and heated lamps within the cabinet were utilised alongside hot water bottles and bellows (for cooling). Learning to eat and drink also required adjustment, as users had to learn how to adjust their swallowing to fit with the rhythms of the machine. ${ }^{62}$ The complicated relationship between breathing and eating was memorably described by home ventilation user David Brooks in 1990:

In addition to breathing, body movements, walking and talking, the most energy sapping activity is surprisingly eating. Having lost so much weight following lung cancer, the removal of my right lung and radiotherapy, it rather added insult to injury to find that the mechanics of eating, swallowing and digesting so intimately involved the respiratory system. Exhausted swallowing muscles and pain filled chest muscles convulse along with my uselessly flapping diaphragm. They are my accompaniments to meal times, a constant battle ground between the requirements of nutrition and the insistent distress of respiratory despair. ${ }^{63}$ 
The MRC report also highlighted significant concerns about how best to synchronise an individual's breathing with the rhythm of the machine. If conscious, patients could 'frequently' indicate what pressure felt most comfortable and best matched their personal breathing rate ${ }^{64}$ However, it seems that this did not always lead to a perfect fit, as:

the Patient's breathing will usually be, for a short time, irregular and 'out of step' with the regular breathing of the machine, but cases with respiratory insufficiency readily adapt themselves to the rate of the machine. If the patient's breathing persistently fails to synchronise, it means that he has an adequate power of natural breathing and does not require treatment in the machine. ${ }^{65}$

This reveals the difficulty inherent in standardising measures for a process as individual and variable as breathing. Moreover, the suggestion that users adapt themselves to the rate of the machine indicates that they were expected to modify themselves to fit the technology rather than the other way around. If patients were continually unable to adapt themselves in this way or were apprehensive of doing so, the breathing rate was adjusted slowly and without their knowledge. ${ }^{66}$ Alternatively, they were simply given a sedative, which was 'not required for long, as most patients soon learn to co-operate with the machine'. ${ }^{67}$ Clearly, there was awareness of how distressing these breathing machines could be for users. However, the MRC report insisted that for seriously ill patients 'the relief afforded is so great and so sudden that any psychological stress is quickly banished'. ${ }^{68}$ Perhaps surprisingly given Bragg's reference to noise as a problem, the rhythmical noise of the motor was suggested here to be soothing and conducive to deep sleeping. This assessment is in marked contrast to Brooks' (admittedly much later) description of sleeping in an assisted ventilation unit: 'the noise at night of all these pumps, huffing and puffing, inevitably at different tempos, was rather like a poorly syncopated orchestra with a demented wind section'. ${ }^{69}$ The impact of the noise of the various breathing machines discussed in this chapter is a resounding theme, and the impact that noise had on patients' ability to integrate these machines into their lives has been consistently underestimated by designers. The possibilities for sleeping, holding conversations and disguising prosthetic devices are all diminished as sound is increased. ${ }^{70}$ 
Indeed, the MRC's optimistic analysis is not wholly supported by the details provided in the appendix to their report, which provides quantitative and qualitative details in relation to individual case reports involving use of the Drinker respirator and the Bragg-Paul Pulsator. ${ }^{71}$ There are repeated instances of user rejection in these tables. For instance, one patient survived treatment with the Both type respirator but 'objected strongly to being put in it'. ${ }^{72}$ One patient using the Bragg-Paul Pulsator 'tended to breathe against it' and died after a day of its use. Similarly, another user of the BraggPaul Pulsator had difficulty adjusting to its breathing rate: 'Difficulty in synchronisation of artificial and natural respiration caused discomfort and led to cessation of treatment. ${ }^{73}$ Many patients simply refused to use the machines. Although some patients survived, in other cases this refusal was noted as contributing in their death. In certain cases, the patient is simply noted to have found the machine either a source of 'relief' or as 'uncomfortable', though one specific case noted 'discomfort in machine so severe that patient's removal from it was ordered'. ${ }^{74}$ Another patient was described as 'so terrorstricken by machine that he had to be removed'. ${ }^{75}$ Overall, user experiences of these 'breathing machines' varied considerably. Crucially, the user's inability or unwillingness to use the machines was a repeated motif and clearly affected the viability of this kind of treatment.

One key appeal of the Pulsator was that once worn, the patient was not hindered or inconvenienced by its movements. With an attachment, moreover, it could also be used by two patients at the same time, forcing them to literally conspire together in the original sense of the Latin, con (with) and spirare (breathe). ${ }^{76}$ However, there was concern that positive pressure respiration could depress circulation and reduce cardiac output and blood pressure, a concern which was heightened for bulbar polio patients suffering from circulatory damage. ${ }^{77}$ It was crucial then, the MRC decided, for patients using an artificial respirator to be under the expert management of doctors, nurses and other attendants who were 'acquainted with certain points and difficulties which arise during the use of mechanical aids to respiration', especially when repair was required. ${ }^{78}$ Care was also necessary to ensure that infections, bed sores, vomiting and constipation were managed so as not to cause serious complications, especially in patients with respiratory paralysis. 


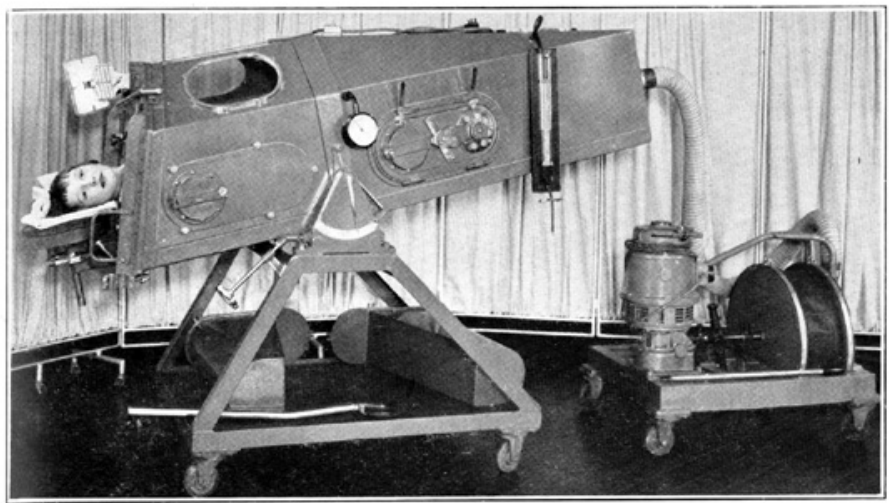

Fig. A.-Drinker Respirator, English Model, as made by Siebe Gorman \& Co., I.td.

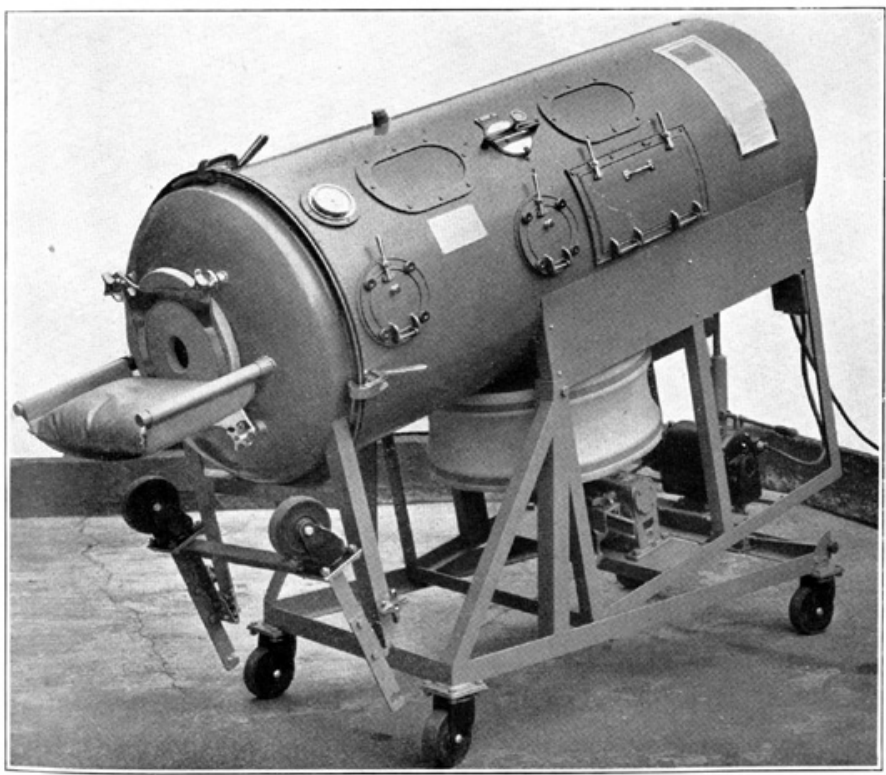

FIG. B.-Drinker-Collins Respirator, Tilting-Rotating Model.

6.1 The Drinker Respirator and Drinker-Collins Respirator (1939) 
The MRC report on "Breathing Machines" and their Use in Treatment', came out in 1939, just as William Morris, the later Lord Nuffield (1877-1963) announced his intent to distribute free of charge 800 Both respirators throughout Britain. Morris manufactured the iron lungs in his car factories and eventually donated more than 5,000 of these devices. ${ }^{79}$ The donation of iron lungs to hospitals throughout Britain allowed for free and easy institutional usage, especially as the MRC recommended that it was more beneficial to bring patients to the hospital rather than to bring equipment to the home. By the end of March 1939, there were approximately 1,000 respirators in the British Isles: 965 Both respirators, 43 BraggPaul Pulsators and 30 Drinker respirators. ${ }^{80}$

\section{From home to hospital}

Bringing patients to the hospital and placing them in these machines became standard practice after the Second World War. However, this solution (while medically and economically advisable) could lead to added distress for families who lost the ability to communicate with their loved ones. Not only were patients quarantined (physically isolated), but it was also difficult for them to communicate with the medical team due to their encasement and reduced visibility in the iron lung. This encasement literally impeded patient voice, as they could only talk on the out-breath of the machine. We can determine the practical consequences of such isolation from cases like that of Dorothy (aged sixteen), who woke in the night of 28 September 1950 with severe back pain. ${ }^{81}$ Over the next two days her pain worsened, until she was vomiting from agony and forced to go to the now-obsolete Ham Green Hospital in Bristol. The attending doctor noted that she had widespread paralysis and diagnosed APM (acute poliomyelitis). Her subsequent isolation caused severe anxiety to her mother, who wrote to the hospital to explain:

when Dorothy was taken away I had 2 shocks first was to be told by her own Dr, that Dorothy was 10 weeks pregnant, second was to hear she had Polio, this has drove me nearly crazey [sic] with worry, as Dorothy was in such awful pain I decided not to say anything to her about being pregnant until she was better, but instead she got worse and was taken away. ${ }^{82}$ 
Plate III

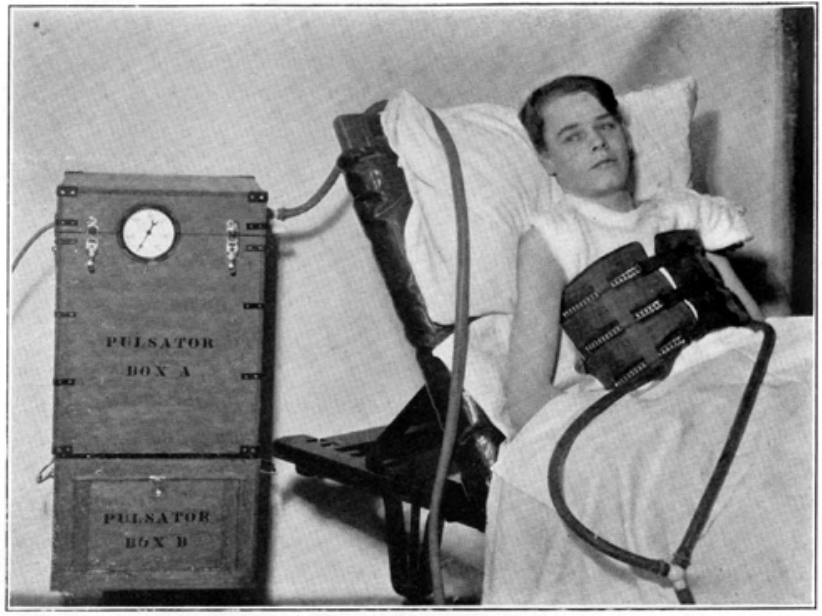

FIG. A.-Bragg-Paul Pulsator.

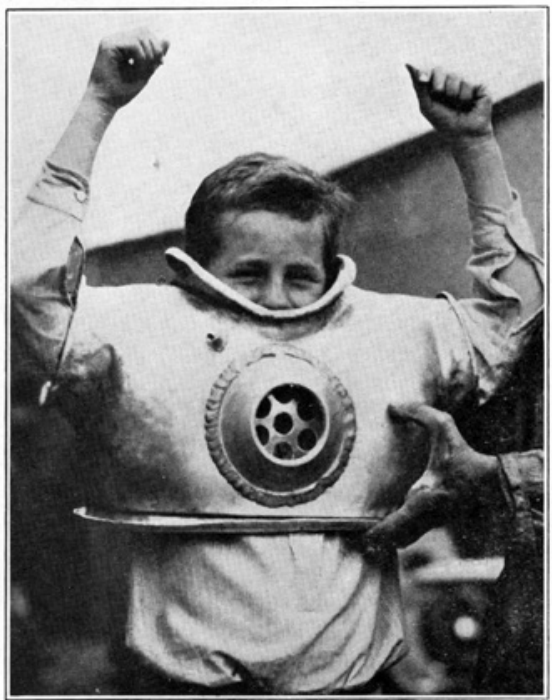

FIG. B.-Burstall Jacket Respirator (being fitted).

6.2 The Bragg-Paul Pulsator and Burstall Jacket Respirator (1939) 
The physician treating Dorothy replied somewhat caustically that 'I can hardly doubt but that Dorothy knows quite well that she is pregnant', but reassured her mother that the paralysis was improving and that Dorothy had not lost the baby. However, by the end of November he decided that it was necessary to terminate the pregnancy to save the patient. It was clear that the patient would not survive artificial respiration while pregnant. In the context of our current struggle against COVID-19 - another virus that compromises respiratory function - Dorothy's suffering is a sobering reminder of the need for accessible emergency abortion and contraception services, even in the midst of a global pandemic. After her abortion, Dorothy's condition rapidly improved, she was able to undergo physiotherapy and after ninety-four days in hospital, she was discharged. Although her experience was undoubtedly traumatic for her and her family (she was described twice in the notes as hysterical), Dorothy's case at least ended with recovery.

By contrast, polio patient Rose (aged twenty-nine) was admitted to the same hospital on 16 October 1950 and was immediately placed in a mechanical respirator. ${ }^{83}$ Her abdominal reflexes were described as 'absent' and she had 'little movement' in her diaphragm. Her distress was such that she was only partially examined before being placed straight into the respirator. While in the respirator, she was given physiotherapy 'in so far as can be managed with patient in respirator' ${ }^{84}$ By December, she could be taken out of the respirator for controlled periods, only initially managing two-three minutes but up to four-five minutes by the end of the month. On 31 December 1950 there was an electricity failure in the hospital which meant Rose 'almost died' before it was possible to get the 'manual operation working'. This may be the reason that six days later she was transferred from the Drinker respirator to the Both respirator - a change which made her both more cheerful and comfortable. However, over the following month she contracted pneumonia and, despite rallying towards the end of January, she had a 'sudden attack of dyspnoea' (breathlessness) at midnight on 1 February 1951, became unconscious, was briefly revived to be described as 'terrified' and subsequently died.

The practice of gradually building up the time the patient spent breathing unaided outside the respirator was a standard treatment for polio patients with respiratory paralysis, especially as it allowed 
them to participate in physiotherapy. ${ }^{85}$ Patients using the respirator were encouraged to stay out for longer periods and once they could remain out for forty-five minutes, they started taking their meals outside the machine. Although adult patients were relatively isolated and relied on epistolary correspondence to communicate with the outside world, parents were able to visit younger children living in the iron lungs, often for extended periods. One such child patient spent 218 days in the hospital in the Drinker respirator. When he died, the attending physician at the hospital described it as a 'welcome event', noting that he 'would never have lived independent of respirator' but that he was 'quite cheerful up to end. Parents helped a great deal by visiting daily without fail' ${ }^{86}$ The child's GP agreed with this assessment and wrote to the hospital physician to thank him for his care and noted, 'I agree with you that it was the best thing that could have happened to the poor child, under the unhappy circumstances'. ${ }^{87}$ These notes illuminate the changing conception of the respirator, from a prosthetic enabling the user to continue life at home, to emergency hospital equipment in which life was considered untenable. Even though these patients were described as cheerful, the iron lung was not being used in the hospital as a prosthetic in the way that Halahan had used his Pulsator at home. However, there is evidence that some contemporary users were using iron lungs to live full and productive lives in this period, as in the case of Mr Fred Suite, who lived in an iron lung for three years before getting married in 1939 and going on honeymoon in a specially weight adapted trailer. ${ }^{88}$ There are also accounts of users of iron lungs and their family members designing home-made personalised machines during this period in Britain. For instance, in $1949 \mathrm{Mr}$ A.F. Evans, a motor engineer in Coventry designed a specific style of iron lung for his daughter which would allow her to live at home. He explained that he had built the device in his garage with some assistance from his employees and his daughter's friend, and emphasised that, 'This new lung I have made covers only the abdomen and chest. It keeps Ann breathing and allows the physiotherapist to give massage and to exercise the limbs to bring fresh life into them'. ${ }^{89}$ Another twenty-six-year-old man in Essex who had virtually no movement except of his head and neck lived at home and was reported to 'frog-breathe for up to three hours but otherwise needs a Tunnicliffe respirator and pump'. ${ }^{90}$ In 
a letter to the editor of the Lancet, his doctor detailed the different organisation involved in his care: 'The County Health Department provide a special nurse; the local council have altered the house; the GPO installed a telephone within 24 hours; the next-door neighbour services the pump; and the Association for the Physically Handicapped have helped in many ways. ${ }^{91}$

However, while some users emphasised the greater portability and independence that chest-only devices offered, others preferred the all-encompassing relief offered by the standard iron lung's negative pressure. For example, Marshall Barr contracted polio in 1949 and began using an iron lung in 1971. He described the experience of encasement as a 'relief' and highlighted the relaxing qualities of its sounds and vibrations, 'Like: ... breathing, bump; breathing, bump ... It was not quite like a smooth breath'. ${ }^{92}$ Paul Alexander, who started using an iron lung in 1952, used it in his university dorm in the United States to pursue a successful career as a lawyer; he still remains in the machine. ${ }^{93}$ In 2017, Martha Lillard, one of three people still using iron lungs in the United States described how the lung provided relief by taking away the effort of breathing for her: 'Imagine if you were real tired of breathing, how good that would feel - if you were struggling to take a breath'. ${ }^{94}$ For Martha and others still reliant on these older technologies, one of the main challenges is finding technicians willing to repair the iron lungs, as the private companies which originally designed them no longer take responsibility for maintaining them. ${ }^{95}$

As this chapter has emphasised, the heterogeneity of respiratory disability experiences proved challenging for the development of standardised treatments. Assorted 'breathing machines' facilitated patient breath while simultaneously impeding patient voice. This historical analysis highlights the importance of prioritising patient voices today, especially when making judgements about quality of life. Caution in this respect is highlighted by the existence of 'the disability paradox'. That is, the fact that many disabled people rate their quality of life as good or excellent although external observers imagine them to have an 'undesirable daily existence'. ${ }^{96}$ This was illuminated by a seminal 1999 investigation in which the disabled people surveyed reported problems related to discrimination, dayto-day activities and society, but nevertheless reported excellent or good quality of life. ${ }^{97}$ At the same time, when asked to imagine the 
wellbeing of disabled people, non-disabled people tend to imagine it to be far worse than it is. This error is exacerbated if the nondisabled person is a healthcare professional and corrected if they have spent time with disabled people. Recent studies have shown that even in states of illness that healthy observers rate as being worse than death, the people with the actual conditions reported similar levels of wellbeing as the healthy counterparts. ${ }^{98}$ Given these findings, this historical episode highlights the crucial importance of centring patient voices and especially disabled voices in all discussions about prosthetic technology. Amplifying disabled voices is especially crucial in situations where resources are scarce. Amid attempts to mitigate the worst effects of the COVID-19 pandemic, the prospect of scarce ventilator resources has meant that decisions to deny life-saving treatment to some disabled people are normalised as an inevitable result of 'triage'. ${ }^{99}$ In such cases it is key, as journalist and disability activist Frances Ryan has argued, that we differentiate decisions about treatment efficacy from judgements about quality of life. ${ }^{100}$ More awareness of the high quality of life experienced by disabled people might change the way we make these assessments. More awareness, too, of the long history of disabled innovation (without which we would lack most of the communication technology we currently rely on so heavily) might also help. Indeed, there is a lot we could learn from disabled people should we chose to listen. However, highlighting the triumphs and innovations of disabled people should not be necessary. Disabled life does not have to be useful to 'count'. As Ryan explains:

In recent days, I have seen disabled people take to social media to list their achievements, as if trying to make the case that they are worth saving. A disabled person who has their ventilator removed during this crisis may have gone on to cure cancer. But then, they may have just been loved. A mum with heart disease who always burns her daughter's birthday cakes. An accountant born with muscular dystrophy who watches Doctor Who every Sunday. Disabled people, like all minorities, are only fully human when we are permitted to be as wonderfully average as anyone else. ${ }^{101}$

Providing adequate funding to enable disabled people to live full lives in their own homes has been a key part of facilitating autonomy and full participation in society. The development of portable oxygen has been a key part of that story, as we will see in the following section. 


\section{Oxygen in the home, 1940-present day}

While the mechanical respirators were a tremendous advance on manual methods previously available for assisting respiration or treating respiratory failure, the eventual confinement of these machines to the hospital posed a challenge for patients facing life-long respiratory paralysis. The shift from hospital to home also coincided with a greater need for patient autonomy, especially as most poliomyelitis and diphtheria survivors were young when first afflicted with the disease. Moreover, when routine polio vaccination was introduced in the 1950s, cases of polio were dramatically reduced and breathing machines for paralysis became less necessary. Thereafter, home respiratory medicine focused more on the use of oxygen to support people who could breathe, but whose lungs could not absorb enough oxygen.

Between 1940 and 1968 oxygen for clinical use was primarily stored in liquid form, kept in cylinders that could be refilled either from a central dispensary, at depots belonging to the British Oxygen Company, or from a larger cylinder stored in patients' homes. ${ }^{102}$ The British Oxygen Company was at that time mainly concerned with providing oxygen and other gases for industry and commerce and its provision of portable oxygen devices was only 'a tiny part of its activities'. ${ }^{103}$ There were repeated calls for new methods of administering clinical oxygen due to difficulties with supply and transportation. However, alternatives to oxygen cylinders (such as oxygen concentrators) were still in the early stages of development. In 1968, a landmark American study showed that oxygen was safe to use in the home in a controlled fashion and argued that portable oxygen concentrators would allow users with Chronic Obstructive Pulmonary Disease (COPD) to increase their activity levels. ${ }^{104}$ However, there were concerns over the cost of developing these new technologies in Britain. ${ }^{105}$

Oxygen usage in Britain was also delayed because of concerns about potentially dangerous side-effects. An increasing number of cases of blindness caused by retrolental fibroplasia in premature infants led to great concern over the use of oxygen therapy. At the start of this period, there was a general consensus that there was almost no risk of oxygen poisoning from continual oxygen use. ${ }^{106}$ However, in the 1950 s studies emerged which confirmed a link 
between the development of retrolental fibroplasia in premature infants and overly high levels of oxygen concentration administered during therapy for respiratory issues. ${ }^{107} \mathrm{~A}$ simple solution to this problem was found by reducing the environmental concentration of oxygen used to treat premature infants. This resulted in a huge reduction in the number of these cases and in addition there appeared to be no adverse effect on mortality rates due to respiratory illness. ${ }^{108}$ However, these incidents created a lasting fear around clinical oxygen usage which persisted into later years and limited the development of certain therapies.

These fears were augmented by concerns over oxygen prescription. Such concerns were highlighted in a House of Commons debate on 10 December 1974, which outlined case studies of patients undergoing home oxygen therapy and discussed the best ways to administer and distribute oxygen systems. Peter Hardy, MP for Rother Valley, instigated this debate due to the plight of one of his constituents, $\mathrm{Mr}$ J. Aisbitt. Mr Aisbitt suffered from a severe case of pneumoconiosis owing to his time as a miner and because of this illness he had extremely poor quality of life. Hardy explained that Aisbitt was unable to leave his home for months at a time because he needed to stay close to the large oxygen cylinders at his home. ${ }^{109}$ Eventually the local branch of the Royal British Legion purchased a portable oxygen appliance (a Portogen appliance from the British Oxygen Company) for Aisbitt so that he might have greater freedom and independence. However, Mr Hardy was greatly concerned that this equipment had to be acquired privately and was not widely available through the NHS. Although patients could be prescribed domiciliary oxygen therapy for the home, Hardy emphasised that there were very few portable oxygen appliances available (less than a dozen in the east of England in 1972-74) and that the devices that were available were used only in the hospitals for emergencies and midwifery cases, 'and not for people who spend most of their time in their own home'. ${ }^{110}$ While Hardy acknowledged that such equipment could be bought privately, he argued that 'many of those disabled by chest disease have been among the poorest in the community for years, perhaps decades, and the $£ 40$ or so involved in purchasing the appliance and recharging equipment could not easily be found by them'. ${ }^{111}$ In response, Alec Jones, the Under-Secretary of State for Health and Social Security, acknowledged problems 
about the lack of portable oxygen devices but emphasised 'that the prescription of breathing appliances is a medical matter'. ${ }^{112}$ As a result, he argued that their administration was best confined to the hospital and warned about the risk of fire hazards from oxygen users refilling portable devices from their main cylinders. He also highlighted possible risks of user dependency and outlined the potential problems associated with supplying portable oxygen outside the hospital. ${ }^{113}$

Primarily these problems related to the administration, maintenance and supply of oxygen therapy. These tripartite concerns reflect those outlined in a 1969 Lancet article on domiciliary oxygen, which discussed both the cost of maintaining oxygen supply as well as the physical inconvenience of the equipment. Its authors maintained that these difficulties were not as insurmountable as commonly perceived. ${ }^{114}$ However, they were also concerned about the variability of user responses and the fact that even those who responded positively to the treatment found the equipment uncomfortable. ${ }^{115}$

Problems related to user response and comfort were also superseded by concerns about equipment costs. Petty and Finigan's original study on continuous oxygen therapy in the United States for the treatment of patients with COPD concluded that, while highly effective as a treatment for COPD, the cost and maintenance of the equipment was a disproportionate financial burden for patients already suffering from a disability which inhibited their ability to work and earn. ${ }^{116}$ Cost efficiency was thus prioritised over usability in the development of newer systems, such as oxygen concentrators. ${ }^{117}$ The oxygen concentrator was first discussed in depth in 1973 by Stark and Bishop in an article that focused on the Rimer-Birlec oxygen concentrator, which was cheaper than the cylinders, but louder and less reliable. While its economic benefits were undeniable, its large size and excessive noise levels meant that few individuals could realistically use this system, as they found the loudness of the noise unbearable. ${ }^{118}$ Though patient comfort was discussed here, it was addressed (as in most studies of this period) in one or two sentences which outlined the need for improvement without offering suggestions for how such improvements could be accomplished. The overriding concern of these studies was not user experience, but rather the challenge of marrying clinical sufficiency with economic sustainability. User experience was considered in terms of the impact of different systems 
on patient quality of life, which was measured using the proxy of hospital visits. For example, one 1975 study demonstrated the positive effect of home oxygen therapy on patients' quality of life by showing the reduction of hospital visits and thus demonstrated that patient benefits were aligned with economic concerns through decreases in hospitalisation. ${ }^{119}$

Cost reduction was a constant concern for those administering oxygen therapy, as they struggled to connect the expense with the variable and individual medical benefits. For instance, a 1978 study in the British Medical Journal praised users who relied on oxygen only intermittently as 'a relatively small drain on resources'. ${ }^{120}$ This study described in detail the process of receiving home oxygen at this time, which involved the user handing in their prescription to the chemist, who would then obtain the cylinder from the British Oxygen Company. At this time the British Oxygen Company enjoyed a virtual monopoly over NHS oxygen usage - something that was criticised in a 1984 debate in the House of Lords during which Lord Young of Dartington pointed out that the company controlled 'nearly 100 per cent of the medical gases which are supplied to the National Health Service' at a cost of $£ 35$ million each year. ${ }^{121}$

Thus, in Britain the focus on patient use and experience was centred around the practicality of administering oxygen and maintaining the equipment in an economically efficient fashion, whereas studies in the United States more seriously considered patients' personal experiences of using the equipment, including the experience of stigma. For example, Petty, Nett and Lakshminarayan's 1973 study was one of the few which discussed patients' reluctance to use two nasal prongs because they were more conspicuous compared to a single prong which could be more easily disguised and afforded a less visible treatment. ${ }^{122}$ British studies offered more focus on the practicality of using these systems. For instance, a 1973 study by Stark, Finnigan and Bishop into long-term domiciliary oxygen for patients with chronic bronchitis gave definite consideration to practicable long-term oxygen treatment in the home and the best methods of administration to allow for a fuller life, though the emphasis was still very much on the medical aspects of the treatment. ${ }^{123}$ A more considerate approach to patient use was previously offered in a 1969 study which evaluated multiple oxygen therapy devices. This study concluded that the nasal cannula was the most 
effective method not because of its clinical benefits, but because it was preferred by patients. That it was the most comfortable method for users made it more effective. ${ }^{124}$ Another Lancet article suggested that for use in public places the apparatus could be made less stigmatising through adaption of 'an inconspicuous palm breathing device instead of a mask'. ${ }^{125}$ Such considerations are crucial. Today, breathlessness is often normalised in communities where smoking is prevalent, which are often low socio-economic areas. ${ }^{126}$ This adds to the invisibility and stigmatisation of COPD, which arises from its association with both smoking and ageing, meaning that users who are prescribed ambulatory oxygen often reject or conceal its use to 'pass' as well. ${ }^{127}$ Management of breathlessness without fear of stigma is critical to successful self-management and the ability to retain a strong sense of self: 'For those with chronic dyspnoea, there is ultimately a sense of the diminishment of identity; of not being able to be the person that they once were or wish to be'. ${ }^{128}$

There were further attempts to improve patient experience when using oxygen therapy in the 1980 Nocturnal Oxygen Therapy Trial (NOTT) of the US National Heart Lung and Blood Institute. This study investigated shorter therapies and took into consideration the need to monitor patients' overall quality of life. ${ }^{129}$ It established that long-term oxygen could improve survival, especially if given continuously (as opposed to only nocturnally or intermittently). The year after this was published (1981) the MRC Working Party released findings from a three-year multi-centre-controlled trail meant to determine whether long-term domiciliary oxygen could improve mortality and quality of life for its users. This was an important and oft-cited study, which demonstrated no evidence of oxygen toxicity and showed reduced mortality in both men and women. Patients in this trail reported 'general improvement in the sense of wellbeing, improved appetite, and general alertness' although the researchers cautioned that these 'subjective impressions, although doubtless very important, could not be quantified' and were not correlated with the proxy measure for quality of life usually used - number of hospital stays. ${ }^{130}$ It also highlighted the fact that oxygen usage seemed to have a greater impact on women, as the 'mortality of the control women was significantly more than that of the treated women from the start of the study', but the low numbers of women 
in the trail (twenty-one versus sixty-six men) meant that it was difficult to determine why this was. ${ }^{131}$

Administering home oxygen therapy to patients proved difficult during this period, as were evaluations of its efficacy. Though there was general agreement that it was beneficial, in many cases concerns over cost, possible risk to patient health and complications with the equipment made it hard for studies to form conclusive results. Concerns over ease of use centred around balancing what was best for patient quality of life with cost limitations. There were concerns about over-administration of oxygen and cost-cutting efforts focused on making sure that the right people were prescribed oxygen therapy and that they were then monitored to ensure proper and consistent use for the most effective results. ${ }^{132}$ One study assessed prescription and usage in the home through questionnaires and home visits from respiratory nurses and found that in some cases patients had not actually been assessed by a respiratory physician, only diagnosed and prescribed treatment of oxygen cylinders 'as standard' to be used sporadically to decrease breathlessness. It claimed that 'although there are established indications for the provision of long-term oxygen therapy with concentrators the indications for treatment with intermittent oxygen using cylinders are less clear'. ${ }^{133}$ Another study called for patients to be reassessed at three months and then again at a year after starting treatment. ${ }^{134}$ Such inconsistencies in the practice of assessing and prescribing oxygen treatment to patients fuelled clinical concerns about over-administration.

Concerns about how patients were being assessed for oxygen therapy merged with concerns about the subsequent rate of compliance. Patient co-operation became an issue at this point only because very little attempt had previously been made to monitor their cooperation. A 1985 article in the Lancet on domiciliary oxygen criticised the guidelines for failing to emphasise strongly enough the importance of patient co-operation. For instance, difficulties arose because many users of oxygen were smokers, who needed to scrupulously avoid smoking while using oxygen to avoid accidental self-immolation. In one study, patients 'denied smoking' but some had not been told how to use their oxygen and two participants used their oxygen less than 'four feet away from an open or gas fire' ${ }^{135}$ Not only did patients need to be able to understand the controls to operate the system; they also needed to be 'dedicated to 
the continuous wearing of nasal prongs or an oxygen mask for fifteen hours a day which will inevitably alter their lifestyle'. ${ }^{136}$ Domiciliary oxygen was still not compatible with what we would consider normal day-to-day activity, thus making it difficult for many patients to accommodate it into their lives. For example, although domiciliary oxygen was supposed to raise activity levels in its users, 'unlike studies in the laboratory' the lengths of tubing were too short to allow them to actually use the oxygen while exercising. ${ }^{137}$ In practice, the tubing was only long enough to allow users to move from one room to another. One 1997 study pointed out that the concentrators short tubing restricted mobility to within six metres and that users found the devices excessively noisy. ${ }^{138}$ Crucially, there was a trade-off between the amount of time the devices could be used and their weight. The 'lightweight' portable oxygen devices $(1.5 \mathrm{~kg})$ lasted for less than half an hour which precluded usage away from the home, whereas the longer lasting devices were too heavy (at $4.5 \mathrm{~kg}$ ) for users with severe respiratory illness to use with any success. ${ }^{139}$ Although the general attitude expressed by medics was that 'half an hour to one hour [...] is adequate for most activities', this limitation did preclude users from making full use of their devices. ${ }^{140}$ Subsequent user resistance presented a problem for those prescribing it as the treatment was only effective when used properly.

Ease of use was an important factor in oxygen administration only so far as it was affordable. Moreover, the individual nature of this treatment made it difficult to create standardised guidelines for assessing and prescribing. Worries that oxygen was becoming a blanket treatment had little impact on the way in which it was prescribed other than to restrict it in ways that were often less than helpful to users. Though more user-friendly administration techniques were developed, they were subject to regional inequalities and often restricted to the private healthcare sector. Poor tolerance to the equipment available often led to patients failing to use their home therapy correctly. Yet the solutions offered were limited, focusing on designing better criteria for assessing and identifying appropriate candidates, as well as better education on use and purpose of oxygen therapy during the course of treatment to promote effective use. ${ }^{141}$ These are hardly solutions developed with users' quality of life in mind. 


\section{Conclusions}

Device usability and patient co-operation remain key factors in the successful uptake of oxygen. Compliance with prescribed oxygen in Britain is very low (just 22 per cent) with one study citing up to 51 per cent of oxygen users still smoking, despite the very high risk of fire and burn injury. ${ }^{142}$ In 2002, another study demonstrated widespread user rejection of ambulatory oxygen from COPD patients who lacked the confidence and instruction to use the devices and were inhibited by the stigma attached to their use. It concluded by emphasising the need to consider the lived experience of people using oxygen and argued that its widespread rejection illustrated 'the pitfalls associated with designing technologies without reference to the ultimate end users'. ${ }^{143}$ As McGuire and Carel have outlined, such rejection often stemmed from the perceived stigma attached to ambulatory oxygen usage, which is noisy and difficult to disguise:

The connotations of severe illness and the accompanying fear of contagion further exacerbate the user's sense that the equipment is stigmatizing. A further sense of shame may arise from the association between respiratory disease and smoking (possibly attributing to the user responsibility for her condition). The relative rareness of such equipment seen outside a hospital increases the interest of and thus questions and comments from strangers, so the user also suffers some loss of privacy and anonymity. ${ }^{144}$

The lack of co-production in initial design has led to ongoing problems around portability, comfort, consideration of stigma and the everyday life of the patient. ${ }^{145}$ Home oxygen has thus been described as simultaneously life-giving and burdensome. ${ }^{146}$ This dual way of relating to oxygen has led sociologist Megan Wainwright to refer to it as a 'limiting enabler' that represents independence and dependence concurrently. ${ }^{147}$ One early adopter of portable oxygen articulated this sense of reluctant attachment to her portable oxygen system, which she named 'Harvey'. She explained:

I cannot get along without Harvey, yet I find I cannot get along with him either [...] Harvey and I have what you would call a love/hate relationship. I call him my friend; but he is not really my friend when I trip over his cord, forget to turn him on [...] he misbehaves and gets tangled up in the market shopping cart. ${ }^{148}$ 
Anthropomorphising oxygen machines in this way is not uncommon. David Brooks, for instance, discussed his relationship with his oxygen machine, Fifi, as that of man and wife. ${ }^{149}$ Another user discussed her oxygen cylinder as if 'she' was a naughty pet and named her Gwendolin. This practice may be related to the need to control the machine and to moderate one's attachment to it. ${ }^{150}$

Although companies such as Invacare have developed much more advanced lightweight mobile oxygen concentrators, these are neither in widespread circulation nor available on the NHS. ${ }^{151}$ In 2006, following the Linde group's takeover of the British Oxygen Company (now BOC), four private companies took over control of the NHS oxygen service in an attempt to both save the NHS money and allow users easier access to oxygen. As part of the privatisation of the service, the country was divided into regions, which went out for tender. Today, Air Liquide meets most of Britain's medical oxygen requirements, but some regions are supplied by BOC or Baywater. In the first month of this transition to a wholly privatised service, one woman died because the delivery of her oxygen was delayed. Many other users reported problems (ranging from inconvenient to life threateningly problematic) because of delayed access to oxygen. ${ }^{152}$ Each company has their own procedures and protocols and they do not communicate with each other. Like trying to use a train ticket bought from one train company on a train run by another train company on the same line, this results in great bureaucratic difficulties when users attempt to work or travel in another company's area. Users must request their oxygen cylinders directly from the oxygen company and this change has had the unintended consequence of destroying the vital social networks that had developed between the pharmacist and the oxygen users. ${ }^{153}$ Users today point out that the current system is designed for the convenience of the oxygen companies rather than its users. It may also exacerbate social difficulties for more precarious users of oxygen as they are personally responsible for informing their landlords if they are using oxygen, but the risk of fire means that private landlords are more likely to refuse leases to oxygen users. ${ }^{154}$ Not only is the timing of oxygen delivery non-negotiable, but the company's scheduling is also predicated on the ableist idea that the oxygen user is non-working and housebound, thus making it even harder for users to lead lives with normal educational or working patterns. Users have a distinct 
lack of control over their oxygen supply, even though its effective provision can be quite literally a matter of life and death. The resulting anxiety often results in users attempting to conserve their supplies by 'hoarding' their oxygen. ${ }^{155}$ Thirteen years later, after that isolated incidence of privatisation, many other parts of the NHS are now under threat from just such 'patchwork privatisation'. Yet the case of oxygen provision and the abandonment of the iron lung users in the United States does not suggest that we should be either optimistic or complacent about this process. ${ }^{156}$

This privatisation and division of medical oxygen has led directly to oxygen shortages in hospitals treating COVID-19 patients, as multiple hospitals have declared critical shortages and some have been forced to limit the number of people treated on mechanical ventilators. ${ }^{157}$ GPs have advised patients who normally use oxygen at home through the NHS to buy it privately because it is so scarce. ${ }^{158}$ This is especially egregious given that we know that most users come from lower socio-economic backgrounds and may be particularly isolated and unable to ask for support. Moreover, an article in the Health Service Journal has argued that while the amount of medical oxygen available in Britain was sufficient, there were problems specifically around the co-ordination of deliveries and availability of engineering staff. ${ }^{159}$ It seems clear that these problems of coordination across regions would be mitigated by a nationalised service with standardised practices and easy ability to communicate. Disabled users have been highlighting these problems out for years. It is past time for us to start listening.

\section{Notes}

* This chapter was written with the generous support of a Wellcome Trust Senior Investigator Award (grant no. 103340; www.lifeofbreath.org). We are grateful to the Trust for supporting the Life of Breath project and to the University of Bristol Faculty of Arts for funding Jenny Hutton's research as the Life of Breath Intern. Coreen McGuire would like to thank Manchester University Press for allowing her to use material from her monograph Measuring Difference, Numbering Normal: Setting the Standards for Disability in the Interwar Period.

1 Bragg described Halahan as his friend and his 'neighbour in the country', Bragg was working in London at this time but may have 
had a second home/main base in West Sussex. Letter from W.H. Bragg to Leonard Hill (4 January 1934), William Henry Bragg RI Admin Correspondence 1933-39, RI MS WHB/27E/5, Royal Institution of Great Britain (thereafter WHB). Information on Samuel Crosby Halahan was retrieved from GENi, www.geni.com/people/Samuel-Halahan/ 6000000015282798567 (accessed 16 February 2021).

2 Letter from Bragg to Hill (4 January 1934), WHB.

3 P. Kerridge, 'Artificial Respiration for Three and a Half Years', Lancet 227:5870 (1936), 504. The discussion of the nurses' continuous artificial respiration is discussed in a newspaper clipping titled 'Iron Lungs' in the William H. Bragg Miscellaneous Correspondence, Bragg-Paul Pulsator (15 March-15 August), RI MS WHB/8B/9, Royal Institution of Great Britain (henceforth WHBMC). See also U. Blackwell, 'Mechanical Respiration', Lancet 254:6568 (1949), 99-102.

4 Maud Ethel Halahan (neé Galton), www.geni.com/people/Maud-EthelGalton/6000000015282765918 (accessed 16 February 2021).

5 Kerridge, 'Artificial Respiration', 504.

6 Paul was internationally renowned for his scientific instruments: including the galvanometer, early wireless telegraphy sets and devices for submarine warfare; he is also famous today as a pioneer of British film, devising cameras and projectors for motion pictures.

7 'Iron Lungs', WHBMC.

8 W.H. Bragg, 'Bragg-Paul Pulsator', British Medical Journal (30 July 1938), 254.

9 Letter from Bragg to Hill (4 January 1934), WHB.

10 Bragg, 'Bragg-Paul Pulsator', 254.

11 Copy of letter from William H. Bragg to Secretary of the British Red Cross Society, addressed to Col. Day (11 July 1938), WHB/8B/4-5, WHBMC. The Red Cross was also interested in Bragg's creation, especially since they helped to commercialise oxygen tents, as indicated by a 17 July 1938 letter from Sir Harold B. Facus, the Director-General of the British Red Cross Society to Bragg, WHB/8B/6, WHBMC.

12 'Iron Lungs', WHBMC.

13 C. McGuire and H. Carel. 'Stigma, Technology and Masking: Hearing Aids and Ambulatory Oxygen', in D. Wasserman and A. Cureton (eds), Oxford Handbook of the Philosophy of Disability (Oxford: Oxford University Press, 2019), 598-615.

14 The branding of the Bragg-Paul device as the 'Pulsator' was owed to physiologist Phyllis Kerridge who worked to improve the physiological dimensions of the machine.

15 For a historical discussion of this nomenclature, see, L.J. Witts, G.R. Girdlestone, R.G. Henderson, P.M. Tookey Kerridge, G.W. Pickering, 
C.L.G. Pratt, E. Schuster, A. Topping and N.F. Smith, “Breathing Machines" and Their Use in Treatment: Report of the Respirators (Poliomyelitis) Committee', Medical Research Council Special Report Series, No. 237 (London: His Majesty’s Stationery Office, 1939), 1-91, 6.

16 Anon., 'On the Comparative Inutility and Extravagant Cost of the Patent Metallic Respirators', Lancet 30:765 (1838), 167-8

17 K. Binnie, C. McGuire and H. Carel, 'Objects of Safety and Imprisonment' (under review with Journal of Material Culture).

18 P. Foster and M. Pooler, 'Muddled Thinking Punctures Plan for British Ventilator', Financial Times (17 April 2020), www.ft.com/content/ 5f393d77-8e5b-4a85-b647-416efbc575ec (accessed 16 February 2021).

19 Ibid.

20 For a review of the divergences between medical history and disability history in the United States, see B. Linker, 'On the Borderland of Medical and Disability History: A Study of the Fields', Bulletin of the History of Medicine 87:4 (2013), 499-535.

21 For an overview of the shortcomings of the social model in this respect, see T. Shakespeare, 'The Social Model of Disability', in Lennard J. Davis (ed.), The Disability Studies Reader (New York: Routledge, 2010), 195-203. For a discussion of the problems of the social model for historians, see J. Anderson, War, Disability and Rehabilitation in Britain (Manchester: Manchester University Press, 2011), 5-6.

22 Cf. the amplified telephones described in C. McGuire 'Inventing Amplified Telephony: The Co-Creation of Aural Technology and Disability', in C. Jones (ed.), Rethinking Modern Prostheses in Anglo-American Commodity Cultures, 1820-1939 (Manchester: Manchester University Press 2017), 70-90; Oliver Heaviside's work in long distance telephony and radio signals explored in G. Gooday and K. Sayer, Managing the Experience of Hearing Loss in Britain, 1830-1930 (Basingstoke: Palgrave, 2017), 8.

23 Witts et al., "“Breathing Machines"', 4.

24 D.M. Oshinsk, Polio: An American Story (Oxford: Oxford University Press, 2006), 61.

25 Ibid.

26 J.E. Klein, J. Echtenkamp, V. Alvin and N. Baird, 'Emergency! An Iron Lung in a Hurry', Iron Lung Web Exhibit, University Of Virginia, Health Collections at the Claude Moore Health Sciences Library (2005), http://historical.hsl.virginia.edu/ironlung/ironlung/pg6.cfm.html (accessed 16 February 2021).

27 The device was originally requested by the South Australian Government in 1938 to combat a devastating poliomyelitis epidemic. 
28 P. Drinker, 'Prolonged Administration of Artificial Respiration', Lancet 217:5622 (1931), 1186-8.

29 The attendant was also essential for enabling toilet function, through bedpans and enemas, see Drinker, 'Prolonged Administration of Artificial Respiration', 1187.

30 M. Barr, 'The Iron Lung: A Polio Patient's Story', Journal of the Royal Society of Medicine 103:6 (2010), 256-9, 256.

31 'Iron Lungs', WHBMC.

32 Kerridge, 'Artificial Respiration', 504.

33 This technique is called glossopharyngeal breathing. See Daniel J. Wilson, Living with Polio: The Epidemic and its Survivors. (Chicago: University of Chicago Press, 2005), 91.

34 Letter from K.N. Knapp to William Bragg (18 September 1933), WHB/27E/4, WHB.

35 Hill mentioned that a similar German apparatus was in existence but had failed because the positive pressure could be injurious to patients, at times inflating the heart with mucus and blood.

36 Poulton also invited Bragg and Paul to present their device at the Therapeutic and Pharmaceutical Section of the Royal Society of Medicine.

37 Letter from Dr Poulton to William Bragg (15 February 1934), WHB/ 27E/7, WHB.

38 Furthermore, Kerridge suggested to Bragg and Paul that an article published in the Lancet, detailing the clinical features of the device without going into too much technical detail - would appeal to general practitioners who would otherwise not learn of it. Letter from Phyllis Kerridge to William Bragg (19 March 1934), WHB/27E/10, WHB.

39 Letter from Paul to Editor of British Medical Journal (30 July 1938), WHB/8B/16, WHB.

40 C.J. McSweeny also argued for the benefits of different sizes, arguing that with the Pulsator, 'the rate of compression can be modified to suit the respiratory rate of the patient $-18,20$, or 22 strokes per minute, as the case may be'. C.J. McSweeny, 'The Bragg-Paul Pulsator in Treatment of Respiratory Paralysis: Report on Thirty-Four Cases', British Medical Journal (1938), 1206-7, 1206; Cf. Witts et al., "Breathing Machines”, 45.

41 "Artificial "Lungs”, Public Health (1938-39), 69-70.

42 Letter from Bragg to Secretary of British Red Cross Society, WHBMC.

43 Letter from William Bragg to S.C. Dyke (7 June 1934), WHB/27E/20, WHB. In $2017, £ 30$ was worth approximately $£ 1,519.88$ according to the national archives currency converter, www.nationalarchives.gov.uk/ currency-converter/\#currency-result (accessed 16 February 2021). 
44 Letter from Siebe Gorman \& Co. Ltd to Robert W. Paul (21 May 1936), WHB/27E/29, WHB.

45 The same company that designed the oxygen mask equipment. Bragg, 'Bragg-Paul Pulsator', 254. On the noisiness of the Drinker respirator see A.A. Gilbertson, 'Before Intensive Therapy?', Journal of the Royal Society of Medicine (1995), 459-63, 461.

46 Letter from Paul to Hutchinson (12 August 1938), WHB 8B/24-26, WHB. Pulsators were distributed to hospitals in Manchester, Birmingham, London, Norwich, Ipswich and Liverpool.

47 The bacteria causing diphtheria releases a toxin that causes a thick grey film (the pseudomembrane) to develop in the throat. As the disease advances and the film sticks to tissues, breathing is obstructed; severe complications include damage to the heart muscles and nerve damage, including paralysis and respiratory failure. Breathing obstruction was such a notable feature of the disease, that it was often called 'The Strangler' or 'Kiss of Death'. In Britain, cases of children admitted with respiratory failure were frequently identified as 'post-diphtheric respiratory paralysis'.

48 'Bragg-Paul Respirator', HC Deb (14 July 1938), 1517-18, https:// api.parliament.uk/historic-hansard/commons/1938/jul/14/bragg-paulrespirator (accessed 16 February 2021).

49 Letter from Robert Paul to C.J. McSweeny (17 July 1938), WHB/8B/8, WHBMC.

50 'Bragg-Paul Respirator', HC Deb (14 July 1938).

51 'Plane's Vain Dash with Respirator', The Scotsman (25 July 1939), accessed via British Newspaper Archive.

52 Letter from Paul to Dr Somerville Hastings (2 January 1938), WHB/27E/66, WHB (re. BBC Broadcast). Paul was sent the transcript by Bragg.

53 Letter from Dr Somerville Hastings to Paul, WHB 27E/66, WHB.

54 Witts et al., "“Breathing Machines”', 3.

55 Review, 'Medical Research Council. Special Report Series no. 237', Indian Medical Gazette (1940).

56 Letter from Robert W. Paul to William Bragg (16 August 1938), WHB/8B/28, WHBMC.

57 Witts et al., “"Breathing Machines”'.

58 Ibid., 2.

59 Wilson, Living with Polio, 91.

60 Witts et al., “"Breathing Machines”', 46.

61 Ibid., 47.

62 Ibid., 51.

63 D. Brooks, 'Living with Ventilation: Confessions of an Addict', Care of the Critically Ill 8:5 (1990), 205-7, 206; D. Brooks, 'The Route 
to Home Ventilation: A Patient's Perspective', Care of the Critically Ill 6:3 (1992), 96-7.

64 Witts et al., “Breathing Machines”, 48.

65 Ibid.

66 Similar tactics were used to wean nervous patients off the machines in which case 'the pressure can, without their knowledge, be gradually reduced until finally the motor is running but no negative pressure is being produced'. See Witts et al., “"Breathing Machines”, 52.

67 Ibid., 49.

68 Ibid.

69 Although there is a fifty-one-year gap between these two reports it is clear from Brooks' description of the machines that there was more continuity of this type of technology than might have been expected. Brooks, 'Living with Ventilation', 207.

70 Victoria Bates' UKRI-funded project (2020-24) on the senses and the modern healthcare environment will provide a welcome intervention into the healthcare soundscape and its impact on user experiences.

71 That these were the only two machines that this kind of data was available for indicates that they were two most widely used machines in Britain at the time of the reports compilation.

72 Witts et al., “"Breathing Machines”, Appendix 'Table A - Continued', 76.

73 Ibid., 90.

74 Ibid., 88.

75 Ibid., 89.

76 'Iron Lungs Will Help Save Midland Kiddies', Birmingham Gazette (4 November 1938), accessed via British Newspaper Archives. Note that, although the headline refers to iron lungs, it was a Bragg-Paul Pulsator which was gifted. Iron lung was often used in the popular press to refer to a variety of style of respirators.

77 J.G. Wilson, 'A Continuing Battle Against the Virus of Polio', The Municipal Journal 59:3 (1951), 1577-81, 1577.

78 Witts et al., “"Breathing Machines”, 43.

79 S. Hurley 'The Man Behind the Motor - William Morris and the Iron Lung', Science Museum Blog (2013), https://blog.sciencemuseum.org.uk/ the-man-behind-the-motor-william-morris-and-the-iron-lung (accessed 16 February 2021).

80 A.A. Gilbertson, 'Before Intensive Therapy?', Journal of the Royal Society of Medicine 88:8 (1995), 459-63, 462.

81 In an exception to the practice not to anonymise in this collection, this patient's name has been changed to preserve her anonymity because the date of this record means that she could potentially still be alive. 
82 Ham Green Hospital Bristol, Records of Poliomyelitis Chicken Pox Herpes Zoster Rubella Mumps 1951, Patient Reg No. 1236/50 Letter to Resident Physician James Macrae inserted into patient records 10/1/1950-1/1/1951.

83 Ham Green Hospital Bristol, Records of Poliomyelitis Chicken Pox Herpes Zoster Rubella Mumps 1951, Patient Reg No. 1298/50 patient records 16/10/1950-2/2/1951.

84 Ibid.

85 Wilson, Living with Polio, 92.

85 Ham Green Hospital Bristol, Records of Poliomyelitis Chicken Pox Herpes Zoster Rubella Mumps 1951, Patient Reg No. $1360 / 50$ patient records 30/10/1950-3/6/1951.

87 Ibid. Letter inserted from Gloucester Road surgery 7/6/1951.

88 Anon., 'Iron Lung Man Wed', Telegraph and Independent, Sheffield (11 August 1939), accessed via British Newspaper Archive.

89 'Home-Made Iron Lung Speeds Girl's Recovery', The Coventry Evening Telegraph (24 August 1949), accessed via British Newspaper Archive.

90 J.C. Graves, Letter to the Editor, 'Domiciliary Rehabilitation of the Respiratory Cripple', Lancet 274:7110 (1959), 1033.

91 Ibid.

92 M. Barr, 'The Iron Lung - A Polio Patient's Story', Journal of the Royal Society of Medicine (2010), 256-9, 256.

92 J. Brown, 'The Last of the Iron Lungs', Gizmodo (2017), https:// web.archive.org/web/20190411011054/https:/gizmodo.com/the-lastof-the-iron-lungs-1819079169 (accessed 16 February 2021).

94 Ibid.

95 Ibid.

96 G.L. Albrecht and P.J. Devlieger, 'The Disability Paradox: High Quality of Life Against All Odds', Social Science and Medicine 48 (1999), 977-88, 977.

97 Ibid., 982.

98 H. Carel, 'Ill, But Well: A Phenomenology of Well-Being in Chronic Illness', in J.E. Bickenback, F. Felder and B. Schmitz (eds), Disability and the Good Human Life (Cambridge: Cambridge University Press, 2014), 243-70, 253.

99 F. Ryan, 'It Is Not Only Coronavirus that Risks Infecting Society - Our Prejudices Do, Too', The Guardian (9 April 2020), www.theguardian.com/commentisfree/2020/apr/09/nice-guidelinescoronavirus-pandemic-disabled (accessed 18 April 2020).

100 Ibid.

101 Ibid. 
102 J.E. Cotes and G.E. Gilson, 'Improved Portable Oxygen Apparatus with Detachable Cylinders for Domiciliary Use', Lancet 271:6947 (1956), 823.

102 Lung Disease (Breathing Appliances), H.C. (10 December 1974), vol. 883, cols 481-482 (col. 475).

104 T.L. Petty and M.M. Finigan, 'Clinical Evaluation of Prolonged Ambulatory Oxygen Therapy in Chronic Airway Obstruction', American Journal of Medicine 45:2 (1968), 242-52.

105 N. Capener, 'Domiciliary Rehabilitation of the Respiratory Cripple', Lancet 274:7104 (1959), 677-8.

106 Annotations, 'Pros and Cons of Liquid Oxygen', Lancet 235:6088 (1940), 842.

107 N. Roberton, J. Gupta, G. Dahlenburg, J. Tizard, 'Oxygen Therapy in the Newborn', Lancet 291:7556 (1968), 1323-9.

108 R.M. Forrester, E. Jefferson and W.J. Naunton, 'Oxygen and Retrolental Fibroplasia: A Seven-Year Survey', Lancet 264:6832 (1954), 258-60.

109 Lung Disease (Breathing Appliances), H.C. (10 December 1974), vol. 883 , cols $481-482$.

110 Ibid.

111 Ibid.

112 Lung Disease (Breathing Appliances), H.C. (10 December 1974), vol. 883, col. 477.

113 Ibid., col. 482.

114 Leading article, 'Domiciliary Oxygen', Lancet 293:7594 (1969), 560.

115 W. O'Donohue, J. Baker, G. Bell, O. Muren and J. Patterson, 'The Management of Acute Respiratory Failure in a Respiratory Intensive Care Unit', Chest (1970), 603-10.

116 T.L. Petty and M.M. Finigan, 'Clinical Evaluation of Prolonged Ambulatory Oxygen Therapy in Chronic Airway Obstruction', American Journal of Medicine 45:2 (1968), 248-9.

117 M.J. Fox and G.L. Snider, 'Respiratory Therapy: Current Practice in Ambulatory Patients with Chronic Airflow Obstruction', JAMA 241: 9 (1979), 937-8.

118 R.D. Stark and J.M. Bishop, 'New Method for Oxygen Therapy in the Home Using an Oxygen Concentrator', British Medical Journal (1973), 105-6.

119 B.N. Stewart, C.I. Hood and A.J. Block, 'Long-term Results of Continuous Oxygen Therapy at Sea Level', Chest 68:4 (1975), 486-92, 486.

120 M.M. Jones, J.E. Harvey and A.E. Tattersfield, 'How Patients Use Domiciliary Oxygen', British Medical Journal (1978), 1397-1400.

121 'British Oxygen Company: Prices', HL Deb (8 February 1984), vol. 447 cols 1141-1144 (col. 1142). 
122 T. Petty, L. Nett and S. Lakshminarayan, 'A Single Nasal Prong for Continuous Oxygen Therapy', Chest 64:1 (1973), 146-7.

123 R.D. Stark, P. Finnigan and J.M. Bishop, 'Long-term Domiciliary Oxygen in Chronic Bronchitis with Pulmonary Hypertension', British Medical Journal (1973), 467-70.

124 M.S. Shulman, G. Schmidt and M.S. Sadove, 'Evaluation of Oxygen Therapy Devices by Arterial Oxygen Tensions', Diseases of the Chest 56:4 (1969), 356-9, 357.

125 Leading article, 'Domiciliary Oxygen', 560.

126 R. Oxley and J. Macnaughton, 'Inspiring Change: Humanities and Social Science Insights into the Experience and Management of Breathlessness', Current Opinion in Supportive and Palliative Care 10:3 (2016), 256-61, 258.

127 McGuire and Carel, 'Stigma, Technology and Masking'.

128 Oxley and Macnaughton, 'Inspiring Change', 259.

129 The NOTT study group, 'Is 12-Hour Oxygen as Effective as 24-Hour Oxygen in Advanced Chronic Obstructive Pulmonary Disease with Hypoxemia? (The Nocturnal Oxygen Therapy Trial - NOTT)', Chest (1980), 419-20.

130 Medical Research Council Working Party, 'Long Term Domiciliary Oxygen Therapy in Chronic Hypoxic Cor Pulmonale Complicating Chronic Bronchitis and Emphysema', Lancet 317:8222 (1981), 681-6.

131 Ibid., 682. There is not sufficient scope to explore this issue in depth here, but for more consideration of historical developments in terms of gendered differences in care see C. Mcguire, Measuring Difference, Numbering Normal: Setting the Standards for Disability in the Interwar Period (Manchester: Manchester University Press, 2020).

132 Anon., 'Long-term Domiciliary Oxygen Therapy', Lancet 2:8451 (1985), 365-7; J. Escarrabil, R. Estopa, M. Huguet and F. Manresa, 'Domiciliary Oxygen Therapy', Lancet 326:8458 (1985), 779.

133 A.A. Okubadejo, E.A. Paul and J.A. Wedzicha, 'Domiciliary Oxygen Cylinders: Indications, Prescription and Usage', Respiratory Medicine (1994), 777-80.

134 G.H. Guyatt, M.L. Nonoyama, C. Lacchetti, R. Goeree, D. Heels-Ansdell and R. Goldstein, 'A Randomised Trial of Strategies for Assessing Eligibility for Long-Term Domiciliary Oxygen Therapy', American Journal of Respiratory and Critical Care Medicine 72:5 (2005), 573-80.

135 Jones, Harvey and Tattersfield, 'How Patients Use Domiciliary Oxygen', 1398.

136 Anon., 'Long-Term Domiciliary Oxygen Therapy', 367.

137 Jones, Harvey and Tattersfield, 'How Patients Use Domiciliary Oxygen', 1399. 
138 R.J. Shiner, U. Zaretsky, M. Mirali, S. Benzaray and D. Elad, 'Evaluation of Domiciliary Long-Term Oxygen Therapy with Oxygen Concentrators', Israel Journal of Medical Sciences 33:1 (1997), 23-9.

139 Jones, Harvey and Tattersfield, 'How Patients Use Domiciliary Oxygen', 1399.

140 Leading article, 'Domiciliary Oxygen', 560.

141 S. Booth, H. Anderson, M. Swannick, R. Wade, S. Kite and M. Johnson, 'The Use of Oxygen in the Palliation of Breathlessness: A Report of the Expert Working Groups of the Scientific Committee of the Association of Palliative Medicine', Respiratory Medicine 98:1 (2004), 66-77, 73.

142 A.J. Lindford, H. Tehrani, E.M. Sassoon and T.J. O'Neill, 'Home Oxygen Therapy and Cigarette Smoking: A Dangerous Practice', Annals of Burns and Fire Disasters 19:2 (2006), 99-100, 99. For interesting analysis of UK regional inequalities in oxygen and cigarette related burns, see B.G. Cooper, 'Home Oxygen and Domestic Fires', Breathe 11 (2015), 4-12.

143 E. Arnold, A. Bruton, M. Donovan-Hall, A. Fenwick, B. Dibb and E. Walker, 'Ambulatory Oxygen: Why Do COPD Patients Not Use Their Portable Systems as Prescribed? A Qualitative Study', BMC Pulmonary Medicine 11:9 (2011).

144 McGuire and Carel, 'Stigma, Technology and Masking', 605.

145 Ibid.; Arnold et al., 'Ambulatory Oxygen'.

146 A. Collier, K. Braeden and J. Phillips, 'Caregivers' Perspectives on the Use of Long-Terms Oxygen Therapy for the Treatment of Refractory Breathlessness: A Qualitative Study', Journal of Pain and Symptom Management 53:1 (2017), 33-9.

147 M. Wainwright, 'Exploring Ambivalent Oxygen-Machine-World Relations Through the Lens of Post Phenomenology', Journal of Material Culture 23:4 (2018), 426-47, 433.

148 T.L. Petty, Adventures of an Oxy-Phile (AARC, 2004), 60.

149 Brooks, 'Living with Ventilation', 205-7.

150 Binnie, McGuire and Carel, 'Objects of Safety and Imprisonment'.

151 Invacare Platinum Mobile Oxygen Concentrator, www.invacare.ie/ respiratory/portable-oxygen-concentrators/invacare-platinum-mobileportable-oxygen-contentrator (accessed 16 February 2021).

152 'Patients Hit by Oxygen Shortage', BBC News (17 February 2006), https://web.archive.org/web/20190128152905/http://news.bbc.co.uk/2/ hi/health/4722700.stm (accessed 16 February 2021).

153 Ibid.

154 See BOC Home Oxygen Service UK, www.bochomeoxygen.co.uk/en/ patients/introductiontobochealthcare/introduction_to_boc_healthcare .html (accessed 16 February 2021); Rosen Law Office, 'Smoking and 
Medical Oxygen: What's a Landlord to Do?', www.rosenlawoffice.com/ smoking-and-medical-oxygen-whats-a-landlord-to-do (accessed 16 February 2021).

155 McGuire and Carel, 'Stigma, Technology and Masking'.

156 A. Nunns. 'The Patchwork Privatisation of our Health Service: A Users' Guide', Keep our NHS Public Report (2007), http://image. guardian.co.uk/sys-files/Education/documents/2007/01/19/Liste Patchworkprivatisation.pdf (accessed 16 February 2021).

157 D. Campbell, 'Coronavirus: London Hospital Almost Runs Out of Oxygen for Covid-19 Patients', The Guardian (2 April 2020), www.theguardian.com/society/2020/apr/02/london-hospital-almostruns-out-oxygen-coronavirus-patients (accessed 17 April 2020); S. Marsh and R. Booth, 'Hertfordshire Hospital Forced to Consider Who Should Be Refused Oxygen', The Guardian (5 April 2020), www.theguardian.com/world/2020/apr/05/hertfordshire-hospital-forcedto-consider-who-should-be-refused-oxygen (accessed 17 April 2020).

158 G. Pogrund and T. Ripley, 'GPs Tell Patients to Buy Their Own Oxygen as NHS Supplies Run Low', The Times (12 April 2020), www.thetimes.co.uk/article/gps-tell-patients-to-buy-their-own-oxygenas-nhs-supplies-run-low-dmznjgs0h (accessed 17 April 2020).

159 B. Clover, D, West, J. Illman, 'Oxygen Supply Problems 'the New PPE', Warn Hospital Bosses', Health Service Journal (6 April 2020), www.hsj.co.uk/oxygen-supply-problems-the-new-ppe-warn-hospitalbosses/7027333.article (accessed 17 April 2020). 